\title{
THE STYLE FEATURES OF STUDENTS' COGNITIVE ACTIVITY AS THE BASIS FOR FORMATION OF MATHEMATICAL LITERACY
}

\author{
Natalia Podkhodova \\ Herzen State Pedagogical University of Russian Federation, Russian Federation \\ Victoria Snegurova \\ Herzen State Pedagogical University of Russian Federation, Russian Federation
}

\begin{abstract}
Mathematical literacy is the main indicator of the mathematical development of schoolchildren from different countries. In the concept of the direction "mathematical literacy" of the PISA-2021 study, the key component of the concept of mathematical literacy is mathematical reasoning. The development of this skill, first of all, is determined by the stylistic features of the cognitive activity of students in the study of mathematics. Taking them into account in the development of educational material in mathematics will create optimal conditions for the formation of a key component of mathematical literacy. But there are many stylistic features of cognitive activity. Therefore, to develop optimal conditions, taking into account the style features, it is necessary to answer the question: "Which of the style features of cognitive activity have a stronger effect on the effectiveness of solving mathematical problems and how to implement them in educational mathematical activity." In our study, we identified various ways of implementing style features in educational mathematical material, one of the most significant are ways of presenting (coding) information. With this in mind, an experiment was conducted. We applied analysis of variance to its results. The study showed: 1) in general, it is possible to trace relations between successful mathematical problem solving by students with certain individual styles and the way the selected problem is represented; 2) it is necessary to make further research on students' awareness of their personal cognitive characteristics (style features).
\end{abstract}

Keywords: mathematical literacy, components of mathematical content, style features of students' cognitive activity, ways of representation of information (information coding ways).

\section{Introduction}

In the 21st century, significant changes have taken place in the education system: the main guideline of mastering mathematics in secondary school is the formation of functional literacy in students - the ability of students to apply knowledge and skills to solve everyday problems in situations which differ from educational ones. One of the basic components of functional literacy is mathematical literacy, which is interpreted in some studies as the ability of a person to think mathematically, formulate, apply and interpret mathematics to 
solve problems in a variety of practical contexts, in others - as the ability of a person to define and understand the role that mathematics plays in world, make informed judgments, and also ... do mathematics in a way that meets the needs of a person as a constructive, interested and thinking citizen (PISA, 2017).

One of the recognized tools for assessing mathematical literacy in the international educational community is specially designed assignments offered in the framework of international studies PISA.

Almost all countries consider PISA results as an indicator of students' mathematical literacy. And if this indicator is not high enough for students in a country, then the education system of that country is undergoing transformations aimed at increasing this indicator (Fullan, 2011).

Traditionally, an increase in the number of tasks offered to students, similar to PISA tasks, is considered as the main direction of such transformations in the study of the subject of mathematics. Is this way advisable? Unlikely. After all, mathematical activities in general and activities aimed at solving the PISA task include various components. And a competent solution to the problem involves identifying those pain points in the mastery of certain components among students, which together lead to poor results in solving PISA problems, and determining further work to improve the level of mastery of these components.

As a result of the analysis of tasks aimed at the formation of mathematical literacy, we have identified such components as:

1. math content used in problems,

2. the context in which this mathematical content is presented, given in different forms of presentation,

3. student' cognitive activity aimed at analyzing and establishing a connection between the components identified above.

The analysis of the last component made it possible to highlight the specifics of cognitive skills, which are the focus of problems, namely:

- establishing a link between different forms of information presentation.

- translation of the situation into mathematical language (mathematical modeling).

- $\quad$ application of mathematical concepts, facts, procedures of reasoning and justification for solving a mathematical problem.

- interpretation and evaluation of the obtained mathematical result, as well as its use.

In turn, the analysis of the skills required to master the selected mathematical content makes it possible to single out a number of activity components of the mathematical content that underlie the construction of PISA problems (tasks):

1) figuratively - graphic component; 
2) an algorithmic component;

3) an abstract-logical component.

Note that the conditions of tasks corresponding to the first component of the mathematical content, as a rule, are presented in textbooks in a figurativegraphic form, and their solution involves the transformation of graphic information. The conditions of tasks corresponding to the third component of mathematical content, as a rule, are presented in textbooks in symbolic form, and solutions presuppose, in general, the transformation of symbolic information. Tasks corresponding to the second component of mathematical content can be presented in different forms, their solution involves arbitrary transformations of information. Considering that all people are characterized by "individually unique ways of studying reality" and perception and information transformation, which are called "cognitive styles" (Holodnaja, 2004), it was suggested that the levels of mastering different activity components in the same student don't coincide, because different components require different ways of transforming information. Confirmation or refutation of this assumption was put forward as an auxiliary goal of the study. These individually unique ways are determined by the cognitive styles characteristic of the student, and set his individual learning model.

These individual features are attributed to the style features of cognitive activity. Style features also affect the choice of the way present (coding) information by students. To build a system of tasks aimed at mastering different activity components (which means on the development of mathematical literacy), it is necessary to determine which of the style features predominantly determine the choice and effectiveness of the student's solution to the problem given by a certain way of coding information. This determined the main goal of the study.

\section{Literature Review}

The manifestations of ways of coding information in teaching mathematics have been studied by various psychologists and educators (Kruteckij, 1998; Jakimanskaja, 1979). They showed that students of the same age differ sharply in their approach to the analysis of visual material and its use. So some students quickly and easily generalize the material presented in the form of mathematical symbols and signs. Others, on the contrary, learn more easily the material presented in the form of geometric shapes, drawings; still others use verbal material more freely (Jakimanskaja, 1979). The foregoing determines the need to present students with information in various ways of coding. Information presented in only one form of coding may not coincide with the student's presentational system of perception, and then it is not perceived fully enough 
and is not assimilated. In addition, the research of psychologists (Bruner, 2010; Jakimanskaja, 1979, Holodnaja, 2002) showed that it is the mechanism of mutual transition in the system of three ways of coding information that affects the two main lines of the child's intellectual development. Its formation determines, firstly, the growth of conceptual competence through the integration of various forms of experience, and secondly, the growth of individualization of intellectual activity due to the identification of individual styles of information coding. Therefore, the process of teaching mathematics, organized taking into account the style features and the use of different ways of coding information, contributes not only to the mastery of mathematical content, but also to the intellectual development of students.

There are various studies that discuss how thinking styles affect academic performance in Mathematics or intellectual development. Anderson K.L., Casey, M.B., et al. (Anderson, Casey, Thompson, Burrage, Pezaris, Kosslyn, 2008) investigated the relationship between 3 ability-based cognitive styles (verbal deductive, spatial imagery, and object imagery) and performance on geometry problems that provided different types of clues. The purpose was to determine whether students with a specific cognitive style outperformed other students, when the geometry problems provided clues compatible with their cognitive style. The study (Onwumere, Reid, 2014) aimed to explore the concept of field dependency which may offer a way forward in reducing the cognitive demands of finite working memory capacity, thus enabling higher performance to be attained.

However, international studies disagree in terms of how direct influence of cognitive styles correlates to high performance in Mathematics. For instance, study (Jantan, 2007) showed a positive and significant relation between cognitive styles and academic performance of school students, while study (Jantan, 2014) did not reveal any significant effect of cognitive styles on students' performance. Although, all studies showed that Math learning outcomes differ depending on whether students' cognitive styles were taken into account or not when selecting teaching methods.

Western psychological and pedagogical studies adopted the term "learning style” in the 1970s. Dunn R., Dunn K., \& Price G.E. defined learning styles as the student's ability to interact with their educational environment (Dunn, Dunn, \& Price, 1989). J. Hartley distinguished between two close concepts: a cognitive style as typical personal ways to perform cognitive tasks; and a learning style as typical personal ways to perform educational tasks (Hartley, 1998). Later, the study of styles covered a broader field when scholars introduced such concepts as "educational preferences" (Jantan, 2014), "learning styles” (Luver, 1995; Grigorenko, Sternberg, 1995; Kolb A. \& Kolb D., 2005; Peterson, Kolb, 2018), “thinking styles” (Clarke, 2011). One of the key concepts 
to be associated with academic performance is learning style. So far, there is no uniform definition of the "learning style" concept. In fact, learning styles represent models of how a person learns. Initially, the idea was that each individual had a single learning style. But students learn in different ways and depend up on many different and personal factors (Ritu, Sugata, 1999). More recent studies have shown the majority of people are multimodal, meaning they have more than one learning style (Fleming, 2007). However, many years of observation by teachers of Mathematics, including those participating in the PCMAT project, showed that learning styles must be considered in learning process (Martins, Couto, Fernandes, Bastos, Lobo, Faria, Carrapatoso, 2011).

Betty Lou Leaver's (Luver, 1995), study shows that it is necessary to base teaching on an understanding of learning style differences at all learning stages, and at the monitoring stage it is recommended to adapt assessment to the main style of students.

We have identified those style features that are most closely related to the perception of mathematical information and the specifics of the ways it is presented in teaching mathematics. To build a system of tasks aimed at mastering different activity components taking into account the style features, it is necessary to determine which of the style features predominantly determine the choice and effectiveness of the student's solution to the problem given in a certain way of coding? This determined the main question of the research. The answer to it will allow the most economical and effective way to form the ability of students with a certain learning style to transform information to increase the level of mastery in the component formed at a low level.

\section{Methodology}

To achieve the auxiliary goal, an experiment was carried out in which 513 students of grades 8-10 took part in six different schools in St. Petersburg and the Leningrad region. Students were offered tasks of three levels of complexity, involving a demonstration of the skills of the selected components: figurativegraphic, algorithmic and abstract-logical. The success of their performance of tasks of different levels corresponding to different elements of the activity components of mathematical content was recorded. According to the results of the study, each student was assigned a profile: $G_{n}, A L_{m}, A_{k}$. The index shows at what level this or that component is formed. For example, the profile $G_{2}, A_{3}$, $\mathrm{A}_{1}$ shows that the graphic component is formed at the second level, the level of formation of the abstract-logical component corresponds to the second, the algorithmic component is formed at the first level. 
To statistically test the hypothesis of improved learning outcomes when using adaptive tests, the Pearson criterion was used with a probability of error $\mathrm{p}=0.05$ (with a confidence level of 95\%).

To answer the main research question, we ran an experiment in 2020. The goal is to reveal the preferences of students in choosing the type of educational task in connection with their style features. The students were offered three problems identical in mathematical content (generalization of properties of functions), but different in the way the information was presented - problem A was presented in a graphical form, B - in a symbolic form, C - in a verbal form. The experiment recorded what problem the students selected and whether they solved the problem correctly or failed.

Style features to be considered:

- $\quad$ leading channel of perception (auditory, visual, kinesthetic);

- $\quad$ prevalence of an intuitive or logical approach to problem solving;

- $\quad$ prevalence of a synthetic or analytical approach to problem solving.

These parameters were measured based on self-esteem of students under the experiment; in order to identify an individual learning style, the experiment applied "Review of a Learning Style" (Rebecca L. Oxford) (Sirotjuk, 2001). Using the Learning Styles Questionnaire (LSQ) adapted in Russian, the experiment identified learning styles by Kolb (Kolb A. \& Kolb D., 2005): activist, thinker (reflexive), theorist and pragmatist (Learning Styles Questionnaire, LSQ) (Ishkov, Miloradova, 2015).The experiment involved 105 students of grades $8-10$, including 54 boys and 51 girls.

We applied variance analysis to the results, where independent variables were selection of the problem by the students $(\mathrm{A}, \mathrm{B}, \mathrm{C})$ and correct solution of the selected problem (0 - wrong solution, 1 - correct solution); while dependent variables were four groups of style features. It is worth noting that none of students under the experiment selected problem $\mathrm{C}$ presented in a traditional verbal form, typical of course books. Most of the students (63\%) selected problem A, others problem B.

\section{Research Results}

As a result of an auxiliary study, it turned out:

- almost $60 \%$ of students cope with the tasks for the manifestation of the algorithmic component, the level of complexity of which is more than 1 lower than the level of complexity of the mathematical problems they solve for the manifestation of the abstract-logical component;

- about $10 \%$ of students cope with tasks for the manifestation of the algorithmic component, the level of complexity of which is more than 
1 lower than the level of complexity of the mathematical problems they solve for the manifestation of the figurative-graphic component;

- $\quad$ about $10 \%$ the level of complexity of mathematical problems aimed at the manifestation of the figurative-graphic component, more than 1 lower than the level of complexity of the mathematical problems they solve for the manifestation of the abstract-logical component;

- the algorithmic component was formed worst of all: $85 \%$ of students had the algorithmic component formed at level 1 or lower. Level 1 of the algorithmic component implies a conscious reproduction of a known algorithm in a standard situation.

In the study, we also considered the transitional levels of component formation: 0-1, 1-2 and 2-3. Taking this into account, 216 different profiles of component formation are possible. Of the 513 participants in the study, cases of the same level of all three components (for example, 2-2-2) occurred only 6 times. At the same time, no more than 6 of the same profiles were diagnosed. As a rule, in each separate group (class) with the number of students no more than 30 , there were no matching profiles.

Let us give examples of such situations. The table shows the levels of formation of the selected components of mathematical content for several students.

\section{Table 1 Results of the Study of the Levels of Formation of Components Mathematical Content (fragment)}

\begin{tabular}{|c|c|c|c|}
\hline & $\begin{array}{c}\text { level of the graphic } \\
\text { component }\end{array}$ & $\begin{array}{c}\text { level of the abstract- } \\
\text { logical component }\end{array}$ & $\begin{array}{c}\text { level of the algorithmic } \\
\text { component A }\end{array}$ \\
\hline 1 student & 1 & $2-3$ & $0-1$ \\
\hline 2 student & $0-1$ & $1-2$ & 1 \\
\hline 3 student & $1-2$ & 2 & $0-1$ \\
\hline 4 student & 3 & 2 & 1 \\
\hline 5 student & 3 & $2-3$ & 0 \\
\hline 6 student & $2-3$ & 2 & 0 \\
\hline
\end{tabular}

Our main research led to the following results.

When analyzing manifestations of intuitive and logical styles, it turned out students who selected problem A have a more pronounced intuitive style, including those who solved problem A correctly $(\mathrm{F}=8.724, \mathrm{p} \leq 0.006)$.

Analysis of manifestations of auditory, visual, and kinesthetic channels of perception (Fig. 1) showed that students who selected problem A have a more pronounced auditory perception of information $(\mathrm{F}=5.176, \mathrm{p} \leq 0.03)$, however, we can see that the correct solution of both problem A and problem B with auditory learners is significantly lower. 


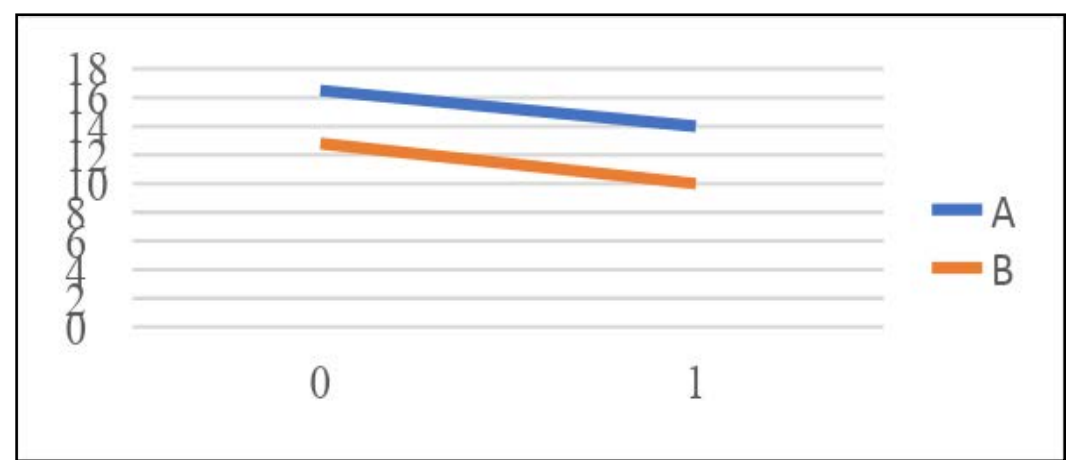

Figure1 Manifestation Degree of Auditory Style Depending on Selection of the Problem and Correct Solution

Among those who chose task $A$, the synthetic style of working with information is more pronounced $(\mathrm{F}=3.867, \mathrm{p} \leq 0.059)$, in addition, we can say that both in solving task A and in solving task B those students turned out to be more successful.

It is interesting that students with a more pronounced analytical style of perceiving information, who preferred problem $\mathrm{B}$ to problem $\mathrm{A}(\mathrm{F}=4.295, \mathrm{p} \leq$ 0.047), turned out to have statistically significant success in solving problems (Fig. 2).

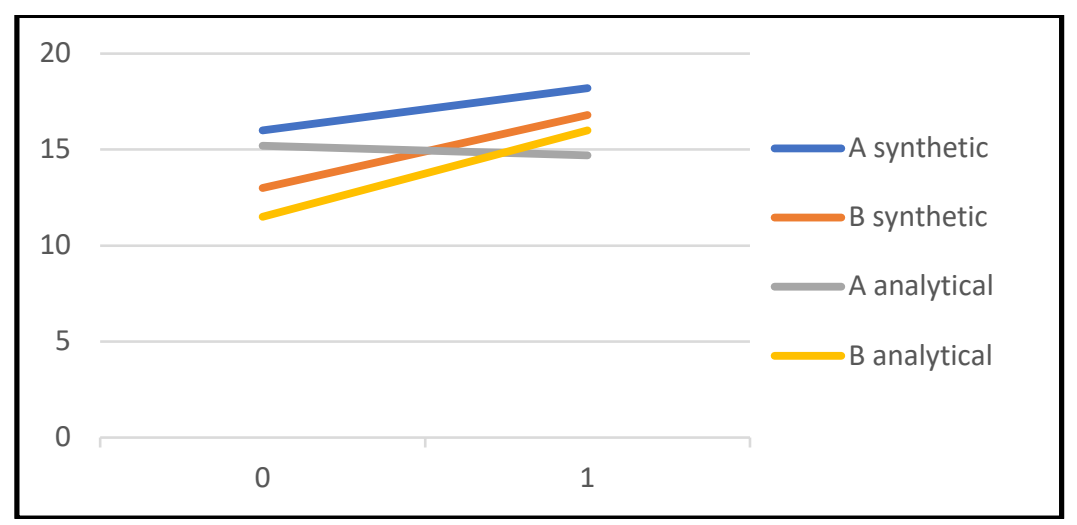

Figure 2 Manifestation Degree of Synthetic and Analytical Style Depending on Selection of the Problem and Correct Solution

Analysis of manifestation degree of learning styles by Kolb showed that among students who selected problem A, pragmatic $(\mathrm{F}=6.42, \mathrm{p} \leq 0.017)$ or theoretical learning style $(\mathrm{F}=11.153, \mathrm{p} \leq 0.002)$ is statistically significant. We can see that students with those styles are more successful in problem solving.

We can also note that among students with a pronounced activist learning style who selected problem $\mathrm{B}$, correct solution of the problem is statistically significant $(\mathrm{F}=5.548, \mathrm{p} \leq 0.025)$ (Fig. 3). 


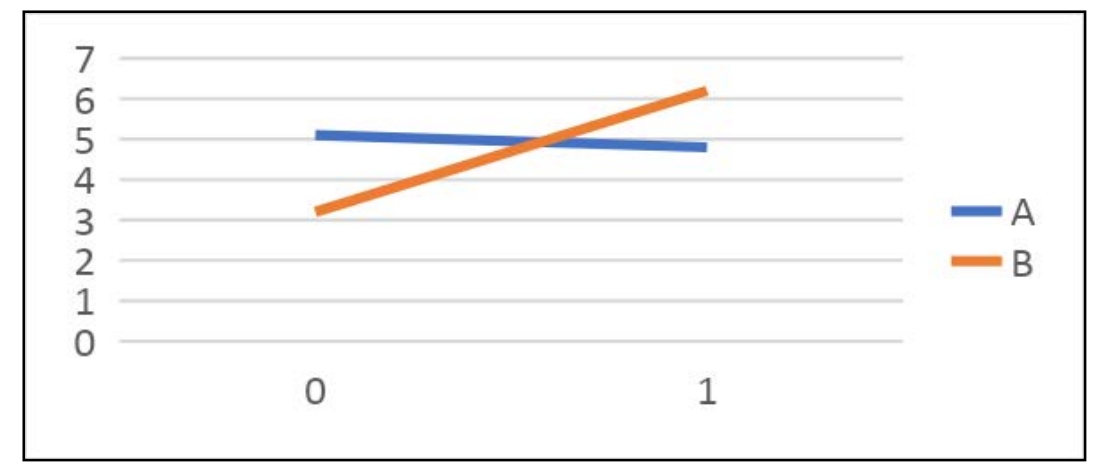

Figure 3 Manifestation Degree of Activist Style Depending on Selection of the Problem and Correct Solution

Analyzing the results, we can state that, in general, it is possible to trace relations between successful mathematical problem solving by students with certain individual styles and the type of problem selected by them. So, students with more pronounced intuitive, synthetic, and pragmatic styles proved to be more successful when selecting problem A, represented in a graphical form matching their preferred style. While students with a more pronounced analytical style were more successful in solving problem B in a symbolic form. Students with a more pronounced auditory style, who erroneously selected problems A and B that do not match their style, were equally less successful in solving them.

However, this relation was not universal, since theorists, who selected problem A in a mismatching graphical form, and activists, who selected problem $\mathrm{B}$ in a symbolic form, solved the problems more successfully.

\section{Conclusions and Discussion}

Thus, in the framework of the auxiliary study, our assumption was confirmed. This means that when working on raising the level of one of the activity components of mathematical literacy, it is necessary to organize competent work, aimed, first of all, at developing style flexibility. To do this, it was necessary to investigate the relationship between a certain style and the success of solving a mathematical problem represented by a certain way of coding.

The study made it possible to show the importance of taking into account style features when organizing work on the development of mathematical literacy. This is confirmed by the revealed dependences of the success of solving problems on the style characteristics of students. At the same time, the aspect of understanding by schoolchildren of their individual characteristics needs additional research, since they did not always choose the closest in style, and 
therefore, a potentially simpler form of assignment for themselves and, as a result, gave the wrong solution.

A practical conclusion follows from this. Knowledge by teachers and familiarization of the students themselves with their style features will not only allow students to better know themselves, but will also contribute to the development of mathematical literacy. This will be achieved through purposeful work with those ways of coding information that do not correspond to the student's style, but are basic for the activity component formed at a low level. An effective technique in this work is the student's reliance on peculiar to him ways of coding through the choice of a problem in peculiar to him form of coding or the translation of this problem into the form of coding peculiar to the student.

\section{Acknowledgements}

This work was supported by the Russian Foundation for Basic Research (grant number 19-29-14080 mk). The funding project is "The computerized adaptive testing of learning outcomes in mathematics, computer science and natural science based on school students' cognitive characteristics.”

\section{References}

Anderson, K., Casey, M., Thompson, W., Burrage, M., Pezaris, E., \& Kosslyn, S.M. (2008). Performance on Middle School Geometry Problems With Geometry Clues Matched to Three Different Cognitive Styles. Mind, Brain, and Education, 2 (4), 188-197.

Bruner, J. (2010). Beyond the Information Given: Studies in the Psychology of Knowing. London: Routledge.

Clarke, M. (2011). Framework for building an effective assessment system. Washington: The World Bank.

Dunn, R., Dunn, K., \& Price, G. (1989). Learning styles inventory. Lawrence, KS: Price Systems.

Fleming, N. (2007). VARK 'A review of those who are multimodal'. Retrieved from http://www.vark-learn.com/english/page_content/multimodality.html

Fullan, M. (2011). Vybor lozhnyh dvizhushhih sil dlja reform celostnoj sistemy (per. s angl. A. Pinskoj). Voprosy obrazovanija, 4, 79-105.

Grigorenko, E.L., \& Sternberg, R.J. (1995). Thinking styles. In D. H. Saklofske\& M. Zeidner (eds.), International handbook of personality and intelligence. New York: Plenum Press. 205-230.

Hartley J. (1998). Learning and studying: A research perspective. London: Routledge.

Holodnaja, M. (2004). Kognitivnye stili. O prirode individual'nogo uma. SPb.: Piter.

Holodnaja, M. (2002). Psihologija intellekta. SPb.: Piter.

Ishkov, A.D., Miloradova, N.G. (2015). Vyjavlenie stilevyh osobennostej vosprijatija, myshlenija i dejatel'nosti s pomoshh'ju oprosnika «SD», Jekonomika $i$ predprinimatel'stvo, 5-1 (58), 432-436. 
Jakimanskaja, I. (1979). Razvivajushhee obuchenie: kniga dlja uchitelja. M.: Pedagogika.

Jantan, R. Md. N. M. (2007). Relationship Between Students "Learning Style and Teachers" Teaching Style With Their Mathematic Achievement. Research Report for Sultan Idris EducationUniversity Grant. Tg. Malim: UPSI.

Jantan, R.B. (2014). Relationship between Students' Cognitive Style (Field-Dependent and Field-Independent Cognitive Styles) with their Mathematic Achievement in Primary School. International Journal of Humanities Social Sciences and Education (IJHSSE), 1(10), 88-93.

Kolb, A., \& Kolb, D. (2005). Learning styles and learning spaces: Enhancing experiential learning in higher education. Academy of Management Learning and Education, 4(2), 193-212.

Kruteckij, V. (1998). Psihologija matematicheskih sposobnostej shkol'nikov. M.: Institut prakticheskoj psihologii.

Martins, C., Couto, P., Fernandes, M., Bastos, C., Lobo, C., Faria, L., \& Carrapatoso, E. (2011). PCMAT - Mathematics Collaborative Learning Platform. In Pérez, J.B., Corchado, J.M., Moreno, M.N., Julián, V., Mathieu, P., Canada-Bago, J., Ortega, A., Caballero, A.F. (eds.) Highlights in PAAMS. AISC, Springer, Heidelberg Cross Ref Google Scholar, 89, 93-100.

Luver, B. (1995). Obuchenie vsego klassa. M.: Novaja shkola.

Onwumere, O., \& Reid, N. (2014). Field Dependency and Performance in Mathematics. European Journal of Educational Research, 3(1), 43-57.

Peterson, K., \& Kolb, D. (2018). Vek zhivi - vekuchis. Per. s angl. N.Braginoj. M.: Mann, Ivanov i Ferber.

PISA. (2017). Reading, Mathematics and Science, Preliminary Version, OECD Publishing, Paris. PISA for Development Assessment and Analytical Framework. Retrieved from https://www.oecd.org/pisa/pisa-for-development/PISA-D-Assessment-and-AnalyticalFramework-Ebook.pdf.

Ritu, D., \& Sugata, M. (1999). Learning Styles and Perceptions of Self. International Education Journal, 1(1). Google Scholar.

Sirotjuk, A. (2001). Obuchenie detej s uchetom psihofiziologii. M.: TC Sfera. 